\title{
Structural Plasticity Underlies Experience-Dependent Functional Plasticity of Cortical Circuits
}

\author{
Linda Wilbrecht, ${ }^{1,2}$ Anthony Holtmaat, ${ }^{1,3}$ Nick Wright, ${ }^{5}$ Kevin Fox, ${ }^{5}$ and Karel Svoboda ${ }^{1,4}$ \\ ${ }^{1}$ Howard Hughes Medical Institute (HHMI), Cold Spring Harbor Laboratory, Cold Spring Harbor, New York 11724, ${ }^{2}$ Ernest Gallo Clinic and Research \\ Center, Department of Neurology, University of California, San Francisco, Emeryville, California 94608, ${ }^{3}$ Department of Basic Neuroscience, CMU, \\ University of Geneva, 1211 Geneva, Switzerland, ${ }^{4}$ HHMI, Janelia Farm Research Campus, Ashburn, Virginia 20147, and ${ }^{5}$ School of Biosciences, Cardiff \\ University, Cardiff CF10 3AX, United Kingdom
}

The stabilization of new spines in the barrel cortex is enhanced after whisker trimming, but its relationship to experience-dependent plasticity is unclear. Here we show that in wild-type mice, whisker potentiation and spine stabilization are most pronounced for layer 5 neurons at the border between spared and deprived barrel columns. In homozygote $\alpha$ CaMKII-T286A mice, which lack experiencedependent potentiation of responses to spared whiskers, there is no increase in new spine stabilization at the border between barrel columns after whisker trimming. Our data provide a causal link between new spine synapses and plasticity of adult cortical circuits and suggest that $\alpha$ CaMKII autophosphorylation plays a role in the stabilization but not formation of new spines.

\section{Introduction}

In the rodent barrel cortex, inputs corresponding to individual mystacial whiskers are spatially segregated in barrels in layer (L) 4 (Woolsey and Van der Loos, 1970). Barrels are ringed by cellpoor septa, which define borders between barrel columns. Whisker trimming causes experience-dependent changes in receptive fields, including potentiation of responses to the deflection of spared whiskers (Glazewski and Fox, 1996). This paradigm has become a classic model for the study of experience-dependent plasticity in the adult neocortex (Fox and Wong, 2005).

In the adult barrel cortex, a subset of dendritic spines appear and disappear over days (Grutzendler et al., 2002; Trachtenberg et al., 2002; Holtmaat et al., 2005). Under baseline conditions, new spines rarely persist for $>8 \mathrm{~d}$ (Holtmaat et al., 2005). Whisker trimming in a chessboard pattern enhances the formation of new persistent spine synapses ( $\geq 8 \mathrm{~d}$ ) on the apical arbors of L5B neurons (Holtmaat et al., 2006), suggesting that the growth of new spines with synapse formation (Knott et al., 2006) could underlie cortical rewiring and receptive field plasticity (Holtmaat et al., 2006; Hofer et al., 2009).

Here we present experiments to further explore the relationship between spine structural plasticity and experience-

Received Dec. 26, 2009; revised Feb. 21, 2010; accepted March 4, 2010.

This work was supported by Howard Hughes Medical Institute (K.S.), the National Institutes of Health [National Institute of Child Health and Human Development, L.W.; National Institute of Mental Health (NIMH), K.S.; NIMH Conte Center, K.F.], and the Medical Research Council (K.F.). We thank Kat Masback and Saroja Bangaru for data analysis, Vincenzo de Paola, Graham Knott, Barry Burbach, and Sandra Kuhlman for assistance with experiments, and Chris Harvey and Cris Niell for comments on the manuscript.

Correspondence should be addressed to Dr. Linda Wilbrecht at her present address: Ernest Gallo Clinic and Research Center, Department of Neurology, University of California, San Francisco, 5858 Horton Street, Suite 200, Emeryville, CA 94608. E-mail: Iwilbrecht@gallo.ucsf.edu.

A. Holtmaat's present address: Department of Basic Neuroscience, University Medical Center, University of Geneva, 1211 Geneva, Switzerland.

D0I:10.1523/JNEUROSCI.6403-09.2010

Copyright $\odot 2010$ the authors $\quad 0270-6474 / 10 / 304927-06 \$ 15.00 / 0$ dependent plasticity. First, we measure response potentiation in neurons near the border between spared and deprived barrels. We report that potentiation is greatest for neurons located nearest the border between columns. Second, we measure the stabilization of new spines as a function of location within the barrel map. Consistent with the data we present on response potentiation, we find that new persistent spine formation after whisker trimming is concentrated within the border between spared and deprived barrels. Third, we compare spine stabilization in wildtype and $\alpha$ CaMKII-T286A mutant mice that lack response potentiation (Glazewski et al., 2000; Taha et al., 2002). We find that in mice that lack response potentiation, there is no increase in new persistent spines at the border between spared and deprived barrels after whisker trimming.

\section{Materials and Methods}

Animals. All procedures for electrophysiological recording were conducted in accordance with the UK's Animal Procedures Act, 1986. All procedures for imaging were approved by the Cold Spring Harbor Laboratory animal care and use committee and followed National Institutes of Health guidelines.

For electrophysiology experiments (Fig. 1), a total of 10 wild-type (WT) C57BL/6J mice, 4 chessboard-deprived animals (P42-P46) and 6 intact (nondeprived) animals (P42-P51) were studied.

For imaging experiments (Figs. 2-4), 1-2 neurons were imaged in 59 male mice, age $2-3$ months. To permit imaging of L5B neurons, mice with an $\alpha$ CaMKII-T286A point mutation (Giese et al., 1998) were crossed with a C57BL/6J transgenic line expressing enhanced green fluorescent protein (EGFP) under control of the Thy-1 promoter (GFP-M line) (Feng et al., 2000). EGFP-expressing mice heterozygous for the $\alpha$ CaMKII-T286A point mutation were crossed to produce sibling mice used for the imaging portion of this study.

Whisker deprivation for electrophysiology experiments. Whiskerdeprived WT mice underwent a typical unilateral chessboard pattern deprivation for a period of $7 \mathrm{~d}$ (Fig. 1). Animals were anesthetized with isoflurane for whisker removal every $2 \mathrm{~d}$. After the deprivation period, 
whiskers were allowed to regrow for 6-9 d before recording. Subjects were housed with littermates during the periods of deprivation and recovery. This deprivation technique has been described previously (Wallace and Fox, 1999), is not known to affect vibrissa follicle innervation, and acts in the same way as whisker trimming by altering sensory activity patterns ( $\mathrm{Li}$ et al., 1995).

Electrophysiology surgery and recording procedure. Anesthesia was induced with isoflurane and maintained with urethane $(0.75 \mathrm{mg} / \mathrm{g}$ body weight). Using a Narishige SR-6 stereotaxic frame, the skull was thinned over the barrel field until transparent and flexible. A small hole was made with a hypodermic needle for each penetration to allow a glass-insulated carbon fiber microelectrode into cortex.

Whiskers were trimmed to similar lengths and stimulated with a $200 \mu \mathrm{m}$ deflection from a piezoelectric stimulator. The principle whisker and all of the immediate surrounding neighbor whiskers were stimulated with fifty 1

$\mathrm{Hz}$ deflections. Extracellular spikes were recorded at a bandwidth of 600 $\mathrm{Hz}$ to $6 \mathrm{kHz}$ and sorted online using a dual threshold spike discriminator (Neurolog). Spike2 software (CED) was used to measure the average magnitude and latency of responses.

Recording penetrations were made into cortical columns that corresponded to either deprived or spared whiskers in the chessboard pattern ( 52 cells); control data were recorded from nondeprived WTs (78 cells).

Cranial window surgery for imaging. Cranial window surgeries and imaging were performed in 8- to 9-week-old mice using ketamine/xylazine as previously described (Holtmaat et al., 2005, 2009). Briefly, the skull overlying the right barrel cortex was replaced by a thin coverglass, leaving the dura intact. Imaging began after a $7-10 \mathrm{~d}$ recovery period. A recent study suggested imaging windows cause spine densities to drop by $>35 \%$ over the first 2 weeks after the surgery (Xu et al., 2007). We were not able to reproduce this data (Holtmaat et al., 2009), and since we report on location- and experience-dependent effects, our data contain internal controls.

Imaging procedure. In vivo images were acquired with a custom-built two-photon laser-scanning microscope with a Ti:sapphire laser, running at $\lambda \sim 910 \mathrm{~nm}$ (Mai Tai, Spectra Physics), and a 40×, 0.8 NA objective (Zeiss). Image acquisition was achieved with custom software (MatLab) (Pologruto et al., 2003). In each mouse, the apical dendritic tufts ramifying in L1 of 1-2 GFP-expressing L5B pyramidal neurons (Fig. 2) were imaged every $4 \mathrm{~d}$, under ketamine/xylazine anesthesia, over a period of at least $28 \mathrm{~d}$. Image stacks consisted of sections $(512 \times 512$ pixels; 0.08 $\mu \mathrm{m} /$ pixel) in $1 \mu \mathrm{m}$ steps. For illustration (Fig. 2), 3-6 median filtered images from a $z$-stack were combined in a projection.

Whisker trimming for imaging experiments. To induce experiencedependent plasticity, we trimmed whiskers contralateral to the imaging window in a chessboard deprivation pattern (Fig. 1b). The ipsilateral mystacial pad was fully trimmed. Whisker trimming was performed under isoflurane anesthesia every $2 \mathrm{~d}$, after a baseline period of three imaging sessions (Fig. 2a). In controls, mock trimming sessions were performed.

Image analysis. A total of 68 neurons were imaged, with three neurons in WT mice followed for a 1-month-long control session, then a 20-dlong whisker-trimming experiment. The total number of experiments was therefore $n=71$. The data were grouped by genotype, whisker trimming, and location in the barrel field. Eleven experiments were performed in untrimmed WTs, 29 in trimmed WTs, 8 in untrimmed T286A $+/+$ mutants, 15 in untrimmed T286A $+/+$ mutants ( 2 without precise location data), and 8 in trimmed T286A $+/-$ mutants. Divisions of these groups made by location are indicated below. The WT experiments also included data from mice that were from the GFP-M line (from Holtmaat et al., 2006), and of which the precise location of the imaged L5B cells in the barrel field was known ( 6 untrimmed and 8 trimmed; these data are distinguished in the figures as triangles). b

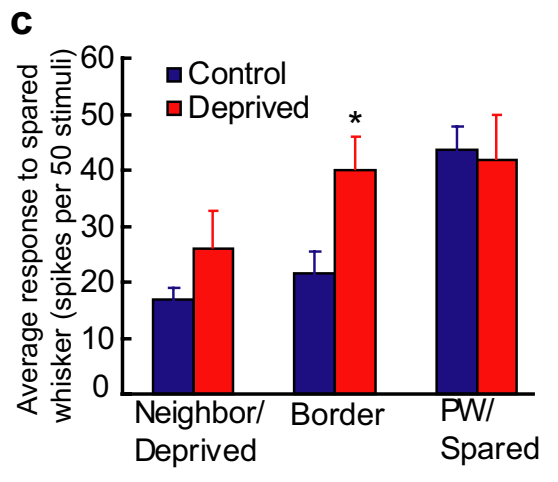

C

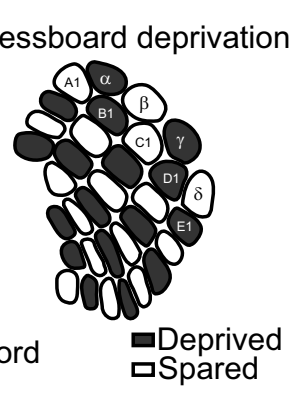
Deprived Spared

\section{L5}

Figure 1. Chessboard whisker deprivation and response potentiation. $\boldsymbol{a}$, Protocol used to induce and record response potentiof the bas spared regions spared

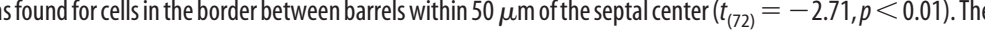
ation in the spared barrel was not affected by deprivation (histogram bars on right).

Spine formation and loss were analyzed for $\sim 26 \mathrm{~mm}$ of dendrite. A cumulative total of 18,070 individual spines were observed over 8-13 imaging sessions (6789 in the first session). Analysis was performed in three dimensions by a blind observer using criteria described by Holtmaat et al. (2009). Turnover ratio was calculated as $\left(N_{\text {gained }}+N_{\text {lost }}\right) /$ $2 N_{\text {total }}$, where $N_{\text {gained }}$ is the number of new spines, $N_{\text {lost }}$ is the number of lost spines, and $N_{\text {total }}$ is the total number of spines (supplemental Figs. 3, $7 a$, available at www.jneurosci.org as supplemental material).

We reconstructed the morphology of the apical tuft from two-photon image stacks, calculating the total length of all second- and higher-order branches, the total number of all branch points, and the vertical separation between the first bifurcation in the apical dendritic tree and the cortical surface (Neurolucida). We verified that all groups contained neurons with similar arbor complexity (supplemental text, supplemental Fig. 6, supplemental Table 1, available at www.jneurosci.org as supplemental material).

Location of neurons in the barrel field. All microelectrode penetrations were marked by lesions following recording ( $1 \mu \mathrm{A}, 10 \mathrm{~s}$ tip negative), and tangential sections of barrel field were reacted for cytochrome oxidase (CO) activity to localize barrels L4 (450-680 $\mu \mathrm{m}$ from the pia). The center of penetration lesions to septal center was measured by a blind observer. Imaged neurons were similarly located by identifying GFP+ apical dendrites in L4 (Fig. $3 b-d$ ). Precise edges of CO-positive barrels were defined by adjusting the barrel profiles to $75 \%$ of the area within septal centers (Holtmaat et al. (2006). In our sample, imaged neurons judged in the septal-associated border between barrel columns had apical dendrites that fell within $50 \mu \mathrm{m}$ from the septal center (range: 36 to -26 $\mu \mathrm{m}$, mean: $5 \pm 5 \mu \mathrm{m})$.

Statistics. For electrophysiology data, we used Student's $t$ test for pairwise comparison.

For analysis of spine data, we used a Kruskal-Wallis test, followed by a Bonferroni contrast (Analyze-It). Significance was set at $p=0.05$. We report $p$ values corrected for multiple comparisons and mean \pm SEM.

\section{Results}

To investigate the effect of whisker deprivation on response potentiation in L5 neurons, we recorded the average number of spikes elicited in response to 50 whisker deflections in the barrel cortex of mice that had whisker deprivation and intact controls (Fig. 1a,b). L5 receptive fields were typically comprised of a principal whisker and 1-8 surround receptive field (SRF) whiskers in intact mice (average $\mathrm{SRF}$ size mean $\pm \mathrm{SD}=2.6 \pm 2.2$ ). Stimulation of the principal whisker produced the shortest latency response for $74 \%$ of L5 cells, similar to findings in rat barrel cortex (Wright and Fox, 2010). 
a

Imaging day

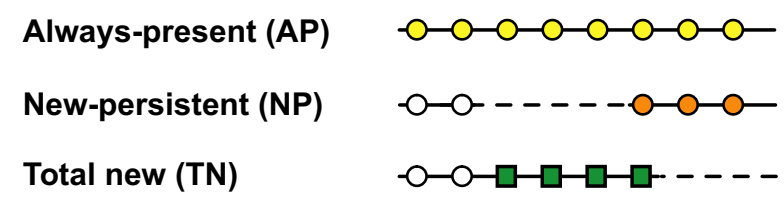

Present $\bigcirc$ Absent $O$ New
Deprived or Intact control
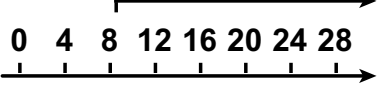
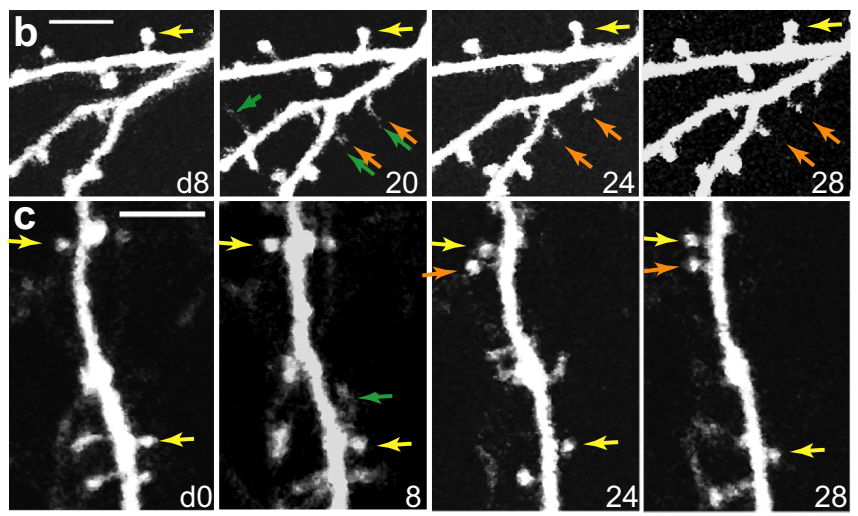

Figure 2. In vivo imaging protocol and analysis of new spine formation and stabilization. $\boldsymbol{a}$, Timeline for imaging and definitions of spine categories. Spines observed during every imaging session were AP (yellow circles and arrows); spines that were first observed on imaging day 8 or thereafter, and were present for the last $8 \mathrm{~d}$ of imaging were NP (orange); TN spines (green) include all spines that were first observed between day 8 and $20 . \boldsymbol{b}, \boldsymbol{c}$, Examples of spine categories in $\boldsymbol{a}: \boldsymbol{b}$, Images from a WT mouse. $\boldsymbol{c}$, Images from an $\alpha$ CaMKII-T286A $+/+$ mouse. Scale bars, $5 \mu \mathrm{m}$.

Following chessboard deprivation (Fig. 1b), the response to the regrown principal whisker was strongly depressed to $32 \%$ of control values in L5 (data not shown) similar to previous findings (Wright et al., 2008). However, the responses to the spared principal whiskers were unchanged and identical to those measured in control mice $\left(t_{(97)}=0.18, p=0.85\right)$ (Fig. 1c). The spared whisker responses were potentiated outside the principal barrel compared to control values in a manner that depended on distance from the spared barrel. As an initial analysis, we compared the responses of cells recorded in the deprived barrel column to stimulation of the two closest spared whiskers in the same row (e.g., D2 and D4 for a cell in the D3 barrel). We found that the average response to the near-side whisker was significantly greater than that to the far-side whisker $\left(t_{(60)}=2.3, p<0.025\right)$ (supplemental Fig. 1, available at www.jneurosci.org as supplemental material). A more detailed analysis revealed that cells located close to the center of the septal border between barrels (within $50 \mu \mathrm{m}$ of the deprived side of the septal center) showed a significant enhancement in spiking response compared to cells in intact controls $\left(t_{(72)}=-2.71, p<0.01\right)$ (Fig. 1c).

\section{After whisker trimming, new persistent spine formation is enhanced on the cells at the border between spared and deprived barrels}

To investigate the effect of whisker trimming on new spine formation, we imaged the apical tufts of complex L5B neurons of adult transgenic mice expressing green fluorescent protein in a sparse subset of neurons in the barrel cortex (GFP-M line) (Feng et al., 2000). Over 1 month, we tracked individual spines, marking all gains and losses (Fig. 2). Whiskers were kept intact during a baseline period of $8 \mathrm{~d}$ (three imaging sessions), followed by $20 \mathrm{~d}$ during which whiskers were trimmed in a chessboard pattern (Fig. $1 b$ ) to induce plasticity. After the imaging experiment, the location of each cell within the barrel map was identified by the location of the apical dendrite as it crossed L4 (Fig. $3 a-d$ ).

We analyzed structural spine plasticity as a function of position within the barrel map. Consistent with previous measurements (Holtmaat et al., 2005), a subpopulation of spines, mostly long and thin, appeared and disappeared over days (fractional turnover between imaging sessions, average all WT d0-4: $0.21 \pm$ 0.011, d4-8: $0.20 \pm 0.012, n=40$ ).

We focused on new spines that were observed for $8 \mathrm{~d}$ or more, since they always bear synapses (Knott et al., 2006) and are likely to persist for a month or longer ("new persistent" spines, NP)
(Holtmaat et al., 2005). We counted "total new" spines (TN, first observed on the day of whisker trimming or thereafter, day 8 to day 20), "always present" spines (AP, observed in all imaging sessions), and NP spines (for definition of spine categories, see Fig. 2a; for spine loss data, see supplemental text, available at www.jneurosci.org as supplemental material). The density of new spines did not vary significantly by group $\left(\mathrm{TN} \mathrm{mm}^{-1}, \mathrm{~K}-\mathrm{W}\right.$ $\chi_{(3,36)}^{2}=3.33, p=0.34$ ) (Fig. 3e). However, the probability that new spines became persistent $(\mathrm{NP} / \mathrm{TN})$ after whisker trimming was higher for neurons in septal columns at the border of barrels than for neurons in deprived columns (NP/TN: septal column neurons: $0.091 \pm 0.007, n=13$, vs deprived column neurons: $0.042 \pm 0.014, n=8, p=0.004$ ) (Fig. 3f; supplemental Fig. $4 d$, available at www.jneurosci.org as supplemental material). Consistent with previous data (Holtmaat et al., 2006), the probability that new spines became persistent in septal columns after trimming was also higher than in nontrimmed controls (NP/TN, $p<$ 0.0001 , untrimmed septal column neurons: $0.029 \pm 0.006, n=11$ ) (Fig. $3 f$ ). Comparisons of trimmed septal column neurons with spared column neurons $(0.058 \pm 0.013, n=8)$ were nonsignificant $(p=0.12)$. Similar results were obtained using other measures of new persistent spine growth (supplemental text, available at www.jneurosci.org as supplemental material). An analysis of soma and individual dendritic branch location within the barrel map showed that NP spine density increases were concentrated on the septal dendrites of neurons in septal columns, but NP spine density increases were not found on dendrites extending from neurons in barrel columns into neighboring septal columns (supplemental Fig. 5, available at www.jneurosci.org as supplemental material). These data show that similar to response potentiation (Fig. 1; supplemental Fig. 1, available at www. jneurosci.org as supplemental material), the stabilization of new persistent spines is most pronounced for neurons close to the border between deprived and spared barrel columns. The precise location of the soma in the barrel map is therefore an important factor shaping experience-dependent plasticity.

$\alpha$ CaMKII-T286A mutant mice that lack response potentiation also fail to gain new persistent spines at the border between spared and deprived barrels

The postsynaptic kinase $\alpha$ CaMKII is critical for long-term potentiation (LTP) (Giese et al., 1998; Lisman et al., 2002; Hardingham et al., 2003) and experience-dependent receptive field plasticity in 


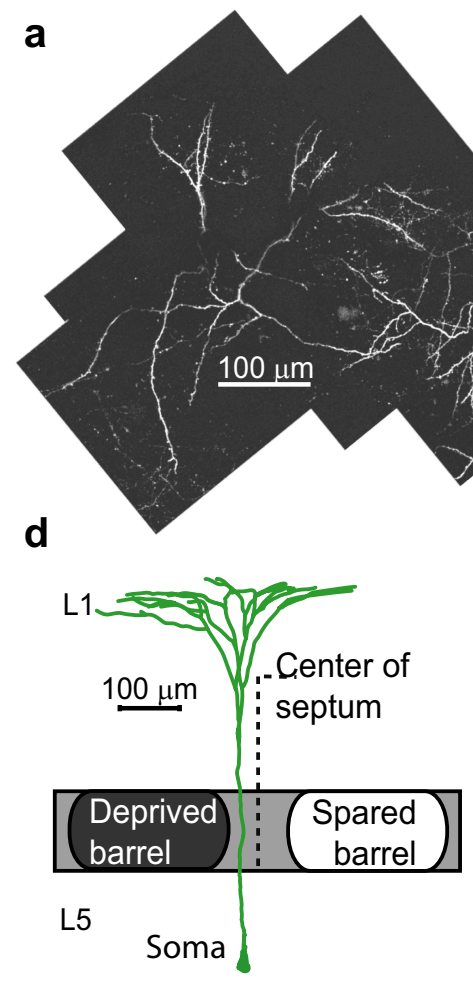

neuron in border between spared and deprived barrels b
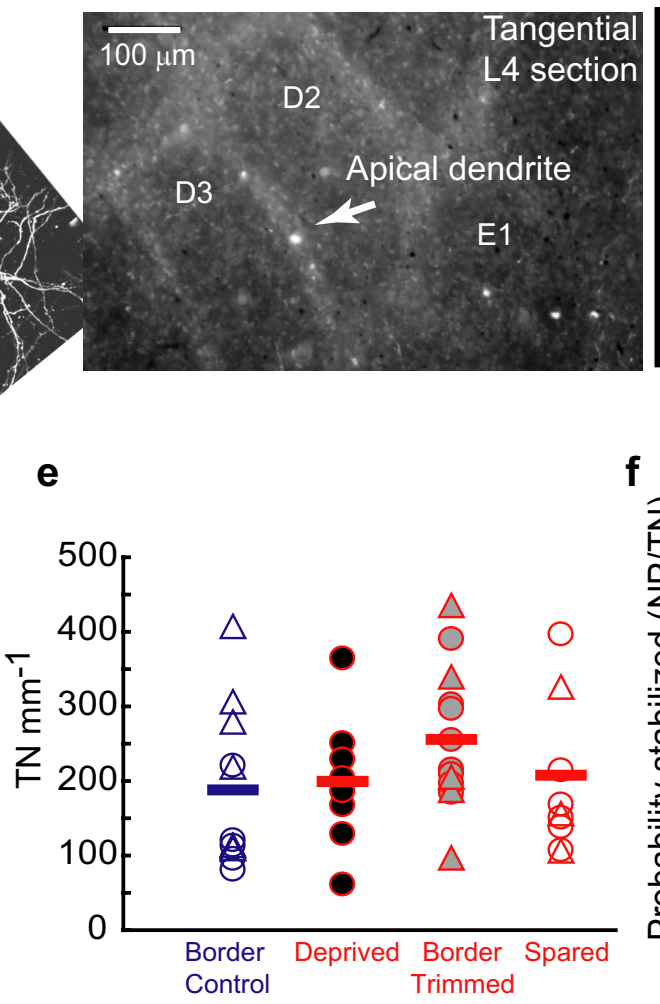

Location in barrel field
C
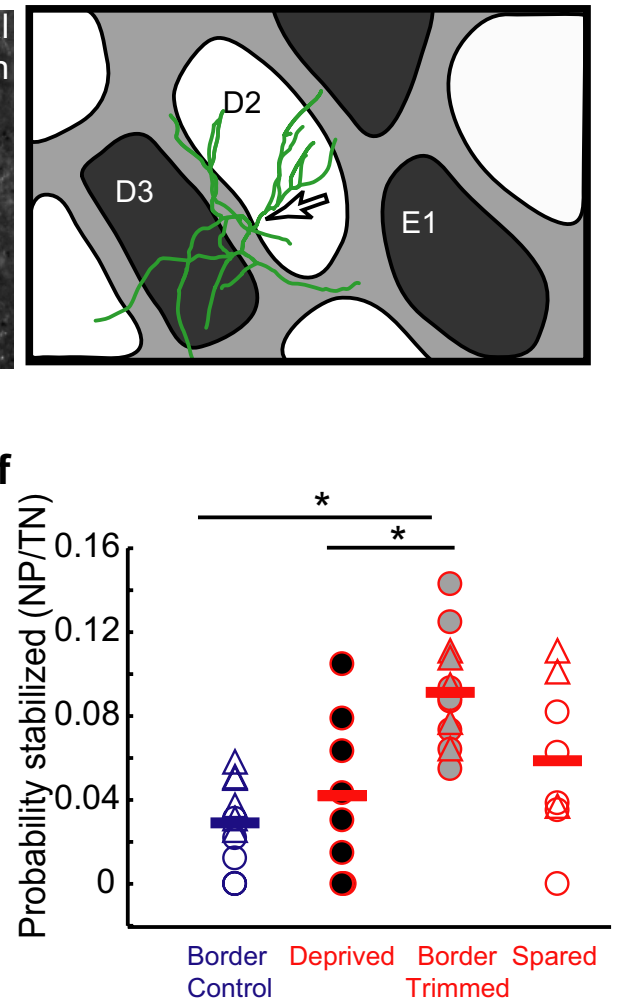

Location in barrel field

Figure 3. The growth of new persistent spines is enhanced near the border between spared and deprived barrel columns. $\boldsymbol{a}$, An overview of $\mathrm{L} 1$ apical arbors of $\mathrm{L} 5 \mathrm{~B}$ neurons imaged in vivo. $\boldsymbol{b}, \mathrm{CO}$-stained tangential section through the L4 barrel field. The arrow points to a GFP-positive apical dendrite of a L5B neuron, corresponding to the left dendritic arbor in $\boldsymbol{a}$ (between barrel D3 and D2). c, The reconstructed L5B neuron placed in a schematic of the barrel field. The apical dendrite travels in the septal column at the border of the two barrels (gray), between spared (white) and deprived (black) barrel columns. $\boldsymbol{d}$, Coronal view of $\boldsymbol{c}$. $\boldsymbol{e}$, The number of total new spines per length of dendrite (TN mm ${ }^{-1}$ ) for neurons in different locations within the barrel field. $\boldsymbol{f}$, The probability that new spines persist after whisker trimming (NP/TN). Each symbol represents a cell. Blue, Untrimmed control; red, trimmed experimental. "Deprived" indicates neurons with apical dendrites that passed through a deprived barrel column in L4 (filled black as in c); "Border," septal column neurons located within $50 \mu m$ of the septal center (filled gray as in c); "Spared," spared barrel column neurons. Triangles, GFP-M transgenic background only; circles, WT mice from the CaMKII-T286A $\times$ GFP-M cross; ${ }^{*} p<0.01$.

the barrel (Glazewski et al., 2000) and visual cortex (Taha et al., 2002). In particular, $\alpha$ CaMKII autophosphorylation at threonine 286 (T286) is necessary for expression of potentiation of responses to spared whiskers after whisker trimming (Glazewski et al., 2000). If response potentiation and new spine stabilization are part of the same adaptive response, we would expect that experience-dependent new spine stabilization would be impaired in homozygous $\alpha$ CaMKII-T286A mice. To test this hypothesis, we imaged spines in GFP-M mice that were crossed with $\alpha$ CaMKII-T286A mutant (T286A) mice and compared five groups: (1) untrimmed WT, $n=11$, all septal (same data as above); (2) trimmed WT, $n=29,13$ septal (same data as above); (3) untrimmed T286A homozygotes (T286A $+/+), n=8$, all septal; (4) trimmed T286A homozygotes $(\mathrm{T} 286 \mathrm{~A}+/+), n=15,9$ septal; and (5) trimmed T286A heterozygotes (T286A $+/-$ ) $, n=8,4$ septal. Dendritic complexity and spine density were similar between groups (supplemental Figs. 6, 7, supplemental text, available at www.jneurosci.org as supplemental material).
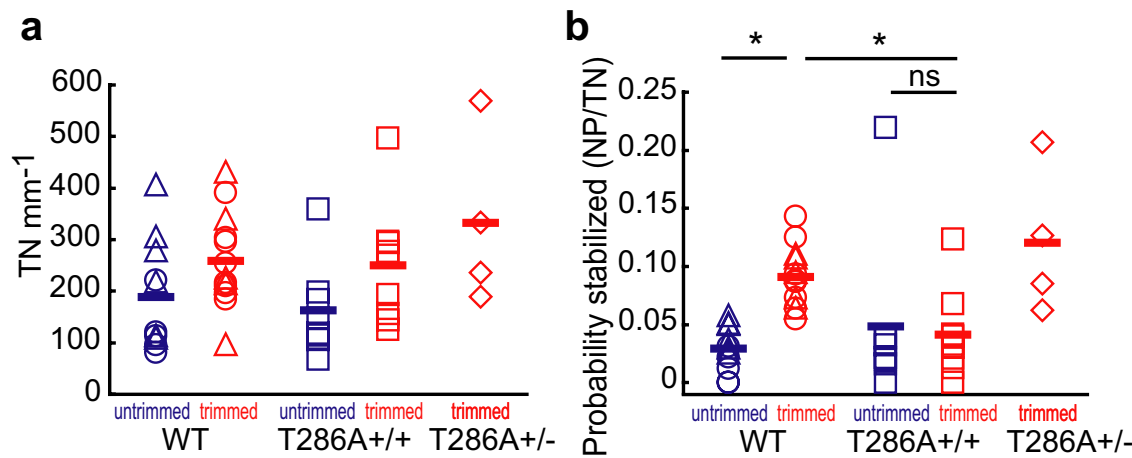

Figure 4. Lack of experience-dependent spine stabilization in $\alpha$ CaMKII-T286A mutant mice. All data are from septal column neurons in barrel border regions. $\boldsymbol{a}$, The number of total new spines per length of dendrite $\left(\mathrm{TN} \mathrm{mm}^{-1}\right) \cdot \boldsymbol{b}$, The probability that new spines persist after whisker trimming (NP/TN). ${ }^{*} p<0.01$; ns, nonsignificant.

The density of new spines and spine turnover ratio did not differ between groups ( $\mathrm{TN} \mathrm{mm}^{-1}$ septal neurons: $\mathrm{K}-\mathrm{W} \chi_{(4,40)}^{2}=$ $8.56, p=0.073$ ) (Fig. $4 a$; for turnover ratio, see supplemental Fig. $7 a$, available at www.jneurosci.org as supplemental material). However, we observed a robust difference between WT and $\mathrm{T} 286 \mathrm{~A}+/+$ mice in the probability that new spines became persistent $(\mathrm{NP} / \mathrm{TN})$ on septal column neurons. In contrast to WT mice (see above), whisker trimming failed to enhance the prob- 
ability that new spines become persistent in T286A $+/+$ mice (NP/TN septal neurons: untrimmed T286A +/+: $0.048 \pm 0.025$, $n=8$, vs trimmed T286A $+/+: 0.041 \pm 0.012, n=9 ; p=1$ ) (Fig. $4 b)$. In trimmed $\mathrm{T} 286 \mathrm{~A}+/+$ mice, the probability that new spines became persistent was significantly lower than in trimmed WT mice (NP/TN septal neurons: $p=0.002)$ and was comparable to untrimmed WT controls (NP/TN septal neurons: $p=1$ ). Other measures of persistent spine gains yielded comparable conclusions (supplemental Fig. 7, available at www.jneurosci.org as supplemental material). These data show that, similar to response potentiation, the stabilization of new persistent spines is absent in homozygous T286A mice. Heterozygous T286A mice show normal surround potentiation in electrophysiology experiments (Glazewski et al., 2000). Consistent with these findings the NP/TN fraction in trimmed T286A $+/-$ and WT mice was comparable (NP/TN septal neurons: $p=1$, T286A +/-: $0.12 \pm$ $0.032, n=4)($ Fig. $4 b)$.

\section{Discussion}

How does the cortex change in response to experience? Classic work has shown that response properties in sensory cortex can change in response to manipulation of activity of inputs (Wiesel and Hubel, 1963; Merzenich et al., 1983; Fox and Wong, 2005). The specific circuits and mechanisms underlying these changes are of great interest as a circuit and cellular model of cortical plasticity and perhaps learning in general.

The topographic organization of the barrel cortex creates a tractable map upon which to induce and isolate experiencedependent changes in cortical response properties. In the mouse barrel cortex, neurons found at the border of barrel columns (septal columns) receive input from the same laminar locations as neurons in neighboring barrel columns (Bureau et al., 2006), and so, in terms of cortical columnar organization, barrel and septal column circuits in the mouse cortex are not different. Subcortical input to L5 neurons does vary according to columnar location. In rats, septal column neurons receive thalamic input from multiple whiskers, while barrel column neurons receive single whisker input from the thalamus, and multiple whisker input from cortical sources (Wright and Fox, 2010). Multiwhisker thalamic input makes neurons in septal columns comparable to neurons in the binocular zone of the mouse visual cortex (Fox and Wong, 2005; Hofer et al., 2009). The interface of multiple distinct inputs onto single neurons may enhance the opportunity for experience-dependent plasticity in subpopulations of neurons across diverse regions of the cortex.

Previous studies have shown that the growth of new persistent spines is enhanced $\sim 10 \%$ after 2 weeks of whisker trimming (Holtmaat et al., 2006) and that new persistent spines have synapses (Knott et al., 2006). These observations suggested that new spine synapses contribute to experience-dependent rewiring of cortical circuits. Layer 1 synapses in the barrel cortex are made by afferents from local L5 and L2/3 axons, thalamic axons as well as feedback from the motor cortex and other cortical areas (Petreanu et al., 2009). It is possible that a $10 \%$ change in synapses corresponds to a much larger fractional change in connectivity between specific cell types.

We conducted three experiments to further explore the relationship between spine structural plasticity and experiencedependent plasticity. First, we measured response potentiation in between spared and deprived barrels and found potentiation is greatest nearest the deprived border. Second, we measured the stabilization of new spines as a function of location within the barrel map. Consistent with the data we present on response potentiation, we found that new persistent spine formation after whisker trimming is concentrated within the border between spared and deprived barrels. Our data are consistent with data from the mouse visual cortex that shows that functional and structural plasticity driven by monocular deprivation is greatest in the cortical binocular zone (Hofer et al., 2009). Third, we compared spine stabilization in wild-type and $\alpha$ CaMKII-T286A mutant mice that lack response potentiation in both barrel (Glazewski et al., 2000) and visual cortex (Taha et al., 2002). We found that in mice that lack response potentiation, there is no increase in new persistent spines at the border between spared and deprived barrels after whisker trimming.

Together these data suggest that experience-dependent functional and structural plasticity is generally greatest for neurons that receive multiple competing inputs. We conclude that new spine growth and experience-dependent stabilization with synapse formation underlies, at least in part, experience-dependent changes in the barrel cortex and likely other sensory cortices (Taha et al., 2002; Hofer et al., 2009).

Our data further show that $\alpha$ CaMKII autophosphorylation plays a critical role in spine stabilization, but not the addition of new spines in vivo. Other studies have shown that CaMKII autophosphorylation is critical for the induction of LTP (Lisman et al., 2002; Hardingham et al., 2003) and the associated spine enlargement (Matsuzaki et al., 2004). Spine enlargement is also a signature of spine stabilization in vivo (Holtmaat et al., 2006; Knott et al., 2006). Together these data suggest a causal link between LTP induction and spine stabilization (supplemental Fig. 8 , available at www.jneurosci.org as supplemental material).

\section{References}

Bureau I, von Saint Paul F, Svoboda K (2009) Interdigitated paralemniscal and lemniscal pathways in the mouse barrel cortex. PLoS Biol 4:e382.

Feng G, Mellor RH, Bernstein M, Keller-Peck C, Nguyen QT, Wallace M, Nerbonne JM, Lichtman JW, Sanes JR (2000) Imaging neuronal subsets in transgenic mice expressing multiple spectral variants of GFP. Neuron 28:41-51.

Fox K, Wong RO (2005) A comparison of experience-dependent plasticity in the visual and somatosensory systems. Neuron 48:465-477.

Giese KP, Fedorov NB, Filipkowski RK, Silva AJ (1998) Autophosphorylation at Thr286 of the alpha calcium-calmodulin kinase II in LTP and learning. Science 279:870-873.

Glazewski S, Fox K (1996) Time course of experience-dependent synaptic potentiation and depression in barrel cortex of adolescent rats. J Neurophysiol 75:1714-1729.

Glazewski S, Giese KP, Silva A, Fox K (2000) The role of alpha-CaMKII autophosphorylation in neocortical experience-dependent plasticity. Nat Neurosci 3:911-918.

Grutzendler J, Kasthuri N, Gan WB (2002) Long-term dendritic spine stability in the adult cortex. Nature 420:812-816.

Hardingham N, Glazewski S, Pakhotin P, Mizuno K, Chapman PF, Giese KP, Fox K (2003) Neocortical long-term potentiation and experiencedependent synaptic plasticity require $\alpha$-calcium/calmodulin-dependent protein kinase II autophosphorylation. J Neurosci 23:4428-4436.

Hofer SB, Mrsic-Flogel TD, Bonhoeffer T, Hübener M (2009) Experience leaves a lasting structural trace in cortical circuits. Nature 457:313-317.

Holtmaat AJ, Trachtenberg JT, Wilbrecht L, Shepherd GM, Zhang X, Knott GW, Svoboda K (2005) Transient and persistent dendritic spines in the neocortex in vivo. Neuron 45:279-291.

Holtmaat A, Wilbrecht L, Knott GW, Welker E, Svoboda K (2006) Experience-dependent and cell-type-specific spine growth in the neocortex. Nature 441:979-983.

Holtmaat A, Bonhoeffer T, Chow DK, Chuckowree J, De Paola V, Hofer SB, Hübener M, Keck T, Knott G, Lee WC, Mostany R, Mrsic-Flogel TD, Nedivi E, Portera-Cailliau C, Svoboda K, Trachtenberg JT, Wilbrecht L (2009) Long-term, high-resolution imaging in the mouse neocortex through a chronic cranial window. Nat Protoc 4:1128-1144.

Knott GW, Holtmaat A, Wilbrecht L, Welker E, Svoboda K (2006) Spine 
growth precedes synapse formation in the adult neocortex in vivo. Nat Neurosci 9:1117-1124.

Li X, Glazewski S, Lin X, Elde R, Fox K (1995) Effect of vibrissae deprivation on follicle innervation, neuropeptide synthesis in the trigeminal ganglion, and S1 barrel cortex plasticity. J Comp Neurol 357:465-481.

Lisman J, Schulman H, Cline H (2002) The molecular basis of CaMKII function in synaptic and behavioural memory. Nat Rev Neurosci 3:175-190.

Matsuzaki M, Honkura N, Ellis-Davies GC, Kasai H (2004) Structural basis of long-term potentiation in single dendritic spines. Nature 429:761-766.

Merzenich MM, Kaas JH, Wall J, Nelson RJ, Sur M, Felleman D (1983) Topographic reorganization of somatosensory cortical areas $3 \mathrm{~b}$ and 1 in adult monkeys following restricted deafferentation. Neuroscience 8:33-55.

Petreanu L, Mao T, Sternson SM, Svoboda K (2009) The subcellular organization of neocortical excitatory connections. Nature 457:1142-1145.

Pologruto TA, Sabatini BL, Svoboda K (2003) ScanImage: flexible software for operating laser scanning microscopes. Biomed Eng Online 2:13.

Taha S, Hanover JL, Silva AJ, Stryker MP (2002) Autophosphorylation of alphaCaMKII is required for ocular dominance plasticity. Neuron 36:483-491.
Trachtenberg JT, Chen BE, Knott GW, Feng G, Sanes JR, Welker E, Svoboda K (2002) Long-term in vivo imaging of experience-dependent synaptic plasticity in adult cortex. Nature 420:788-794.

Wallace H, Fox K (1999) The effect of vibrissa deprivation pattern on the form of plasticity induced in rat barrel cortex. Somatosens Mot Res 16:122-138.

Wiesel TN, Hubel DH (1963) Single cell responses in striate cortex of kittens deprived of vision in one eye. J Neurophysiol 26:1003-1017.

Woolsey TA, Van der Loos H (1970) The structural organization of layer IV in the somatosensory region (SI) of mouse cerebral cortex. The description of a cortical field composed of discrete cytoarchitectonic units. Brain Res 17:205-242.

Wright N, Fox K (2010) Origins of cortical layer V surround receptive fields in the rat barrel cortex. J Neurophysiol 103:709-724.

Wright N, Glazewski S, Hardingham N, Phillips K, Pervolaraki E, Fox K (2008) Laminar analysis of the role of GluR1 in experience-dependent and synaptic depression in barrel cortex. Nat Neurosci 11:1140-1142.

Xu HT, Pan F, Yang G, Gan WB (2007) Choice of cranial window type for in vivo imaging affects dendritic spine turnover in the cortex. Nat Neurosci 10:549-551. 